\title{
Características da presença de repre- sentantes políticos nas redes sociais
}

\section{Sandra Bitencourt*}

Resumo: Este artigo tem o propósito de refletir como e porque candidatos e agentes políticos estão investindo nas redes sociais para se aproximar do eleitor e transitar opinião entre grupos e comunidades. A exposição da privacidade dos candidatos, a busca de laços e intimidade com o eleitor e a oferta de discursos personalizados via internet são sintomas e ao mesmo tempo estratégias nesse novo ambiente que requer maiores cotas de atenção dentro da comunicação políticoeleitoral. A análise da adesão de parlamentares às redes sociais na internet revela um fenômeno atomizado, firmado mais em características pessoais do que em perfil partidário e/ou ideológico. A revisão de conceitos e valores presentes na rede, confrontada com as noções de público, privado e opinião pública são o caminho para refletir sobre esse fenômeno que está em plena construção e que se apresenta como promessa para diminuir a distância entre os cidadãos e os representantes da esfera de decisão política.

Palavras-chave: redes sociais; eleições; comunicação política; opinião pública.

Resumen: El propósito de este artículo es reflexionar sobre cómo y por qué los candidatos y agentes políticos están invirtiendo en las redes sociales para aproximarse al electorado y transmitir opinión entre grupos y comunidades. La exposición de la privacidad de los candidatos, la búsqueda de lazos e intimidad con el elector y la oferta de discursos personalizados via internet son síntomas y estrategias en este nuevo ambiente que cada vez más requiere amplias cuotas de atención dentro de la comunicación político electoral. El análisis de la adhesión de parlamentarios a las redes sociales en internet revela un fenómeno atomizado, afirmándose más en las características personales que en el perfil partidario e/o ideológico. La revisión de los conceptos y valores presentes en la red, confrontada con las nociones de público-privado y de opinión pública son el camino para reflexionar sobre este fenómeno que está en plena construcción y que se presenta como promesa para disminuir la distancia entre los ciudadanos y los representantes de la esfera de decisión política.

Palabras clave: redes sociales, internet, elecciones, comunicación política, opinión pública. 
Abstract: This article has the purpose of reflect how and why candidates and public agents are investing on the social networks to approach the voter and transit opinion between groups and communities. The exposition of privacy of the candidates, the search for bond and intimacy with the voter and the offer of personalized speeches by internet are symptoms and strategies at the same time on this new environment that requires major quotas of attention inside the political-voter communication. The analysis of the adhesion of parliamentarians to the internet's social network reveals an atomized phenomenon, fixing more on personal characteristics than in adherent or ideological profile. The revision of concepts and values on the network, confronted with the notion of public, private and public opinion are the way to reflect about this phenomenon that is on construction and that introduces itself like a promise to reduce the distance between the citizen and the representatives of the sphere of political decision.

Keywords: social networks; internet; political communication; public opinion

\section{Introdução}

As grandes possibilidades financeiras são a justificativa para o apetite das empresas por mais e mais informações sobre os usuários da Internet. O investimento nesse segmento é lucrativo porque permite a exploração de um meio que concentra os dados de milhares de pessoas, revelando toda sorte de preferências individuais e coletivas, e, portanto, os gostos específicos de consumidores. Tudo disponibilizado pelo próprio usuário. É o acesso às vontades, manias, desejos, hábitos e paixões nunca antes tão amplo e facilitado, o que permite mapear e caracterizar de maneira mais precisa os fluxos de consumo potencial de produtos e serviços diversos.

A valorização da comunicação e da interconexão, própria da cibercultura, supera a cautela e revela a intimidade. O importante é interagir. Questão que anima e repercute no sistema de filiação a comunidades, completando a personalidade de maneira satisfatória Se funciona sob o ponto de vista mercadológico e comportamental, nas relações de consumo e interpessoais, não é possível ignorar que as redes sociais se configuram também como uma nova arena para a disputa política. Traçar o perfil do eleitorado, formar e mobilizar comunidades, testar discursos e buscar a participação na construção de propostas e programas de governo passa a ser uma possibilidade concreta, abrangente e inédita nos moldes que as tecnologias de informação permitem. Está análise considera um período anterior ao início 
oficial das campanhas eleitorais no Brasil para Presidência da República, Senado, Câmara Federal, Assembléias Legislativas e Governos estaduais e mais do que mapear recursos, antever planejamentos de mídia online, busca mostrar as motivações e as características da presença de representantes políticos na rede.

Considerando que estamos em um ano eleitoral, é possível observar com maior nitidez o aumento da adesão de políticos, sobretudo candidatos, às redes sociais e o aumento do interesse dos próprios leitores por esses espaços. Conforme levantamento da Secretaria de Comunicação Social da Câmara dos Deputados ${ }^{1}$ muitos políticos estão aderindo ao fenômeno do Twitter, um microblog que pode ser atualizado a todo o momento e possibilita que os internautas sigam os passos dos seus representantes. O número de leitores dos micro blogs dos parlamentares dobrou entre janeiro e 31 de maio deste ano. Antes eram 231.271 seguidores e agora o número ultrapassou os 514 mil. Do outro lado da conexão - de olho nesse crescimento - o número de deputados ativos no Twitter também cresceu. Em janeiro eram 247 deputados 'twitteiros' e até o fim de maio foram encontrados 295 legisladores conectados com a rede. Esse dado representa um considerável aumento de microblogs dos parlamentares que antes eram $48 \%$ e agora são $57 \%$ do total de deputados. O anúncio oficial da página no Twitter da Câmara dos deputados é mais um indicativo de que as redes sociais são vistas como espaços estratégicos de comunicação com o eleitor. No microblog da Câmara, os internautas poderão acompanhar informações sobre votações, eventos, editais e programas institucionais.

São os novos dispositivos tecnológicos que permitem novas modalidades de comunicação, relação e debate. Mas o pressuposto de os canais de emissão estarem abertos não é suficiente para determinar maiores cotas de participação. É preciso haver mobilização para a discussão política. A qualidade dessa relação também é fator determinante para permitir inferir se o fenômeno se configura como uma nova esfera, senão de deliberação, pelo menos de incentivo e iniciativa na escolha de temas que sejam de interesse público. Aliás, os próprios conceitos de público e de opinião pública precisam ser revisitados para melhor compreender esse cenário.

Outros efeitos também se desenham nesse contexto, como a construção de reputação através da exposição da intimidade dos políticos e por outro lado, a renúncia à privacidade pelos usuários para ter acesso gratuito e inédito à internet de uma maneira geral e aos bastidores políticos em particular. Contudo, é essa característica que permite anunciar ou discursar de maneira mais efetiva junto ao cidadão, construindo laços, prestando contas 
e talvez fortalecendo preceitos democráticos.

\section{Privacidade $\mathrm{x}$ visibilidade nas redes sociais}

O Twitter completou quatro anos em 2010. O maior crescimento se deu em 2009²: de cinco milhões de usuários no começo do ano para 65 milhões no fim. Segundo dados divulgados no começo de 2010 pela RJ Metrics, apenas $17 \%$ desses perfis são ativos e $40 \%$ nunca foram atualizados. Mesmo com todos funcionando, esse seria um número pequeno se comparado ao Facebook, mas grande o suficiente para incrementar uma discussão sobre a forma como difundimos e consumimos informação. $\mathrm{E}$ foram os usuários que tornaram essa ferramenta tão relevante para a comunicação. Os usuários inventaram o RT, o retweet, quando uma mensagem é reenviada dando o crédito para o perfil do autor. O Twitter incorporou a ideia em uma ferramenta própria. As pessoas, pela forma como usaram o site, mudaram até o propósito do Twitter: de "o que estamos fazendo agora", um uso trivial, para o que está acontecendo agora, um uso informativo. $\mathrm{O}$ número de usuários do Twitter voltou a crescer em janeiro de 2010, depois de terminar 2009 estagnado. A pergunta é, será essa uma ferramenta com grande potencial para disseminar idéias políticas e ampliar a possibilidade de participação cívica? Ou é apenas mais uma vitrine para exibição da intimidade? Nessa segunda opção, seria território perfeito para celebridades instantâneas e descomprometidas com discussões coletivas.

Contudo, visibilidade não é sinônimo de autoridade na rede. A conclusão de estudo feito pela empresa de monitoramento americana Sysomos, que pesquisou os perfis de famosos como o ator Ashton Kutcher e a cantora Lady Gaga, é de que a maior parte dos seguidores de celebridades do Twitter tem pouca ou nenhuma influência no microblog. Os seguidores de alguns veículos de mídia, por sua vez, têm mais influência que muitos pesos-pesados da mídia digital, conclui o estudo, com base em uma escala de autoridade definida pela empresa e que varia de zero a dez.

A Sysomos ${ }^{3}$ explica que "o ranking de autoridade é calculado com base no número de seguidores, seguidos, atualizações e retweets, entre outras métricas. Um perfil com mais autoridade tem mais influência. O levantamento revela que, apesar de terem um grande número de seguidores, muitos deles têm baixa ou nenhuma autoridade". A Sysomos toma como exemplo Ashton Kutcher (5 milhões de seguidores), Britney Spears (4,8 
milhões) e Lady Gaga (4,4 milhões).

Pela análise da empresa, mais da metade dos seguidores de $\mathrm{Ku}-$ tcher $(53,2 \%)$ têm influência um ou zero, com autoridade média de 1,7; no caso de Britney, esse porcentual é de 52\% e, para a Lady Gaga, de 35,8\%. Especialistas em mídia social, por sua vez, têm a maioria de sua audiência no Twitter com autoridade média (entre 4 e 5). $\mathrm{O}$ diretor de Insights da Edelman Digital, Steve Rubel, por exemplo, tem 20\% de seus 42 mil seguidores com autoridade 4, a mesma de 21\% dos 139 mil seguidores do presidente da New Marketing Labs e coautor do livro "Trust Agents", Chris Brogan.

A empresa conclui que, embora algumas das contas analisadas tenham um grande número de seguidores, elas se diferenciam pelo perfil de seus seguidores - um indicador de que é importante conhecer quem é seu público-alvo e quem poderia influenciá-los mais.

Essas métricas devem ser fundamentais para quem quer tecer uma rede influente para disseminar seu projeto político. Como construir reputação e laços fortes no campo político não tem uma resposta simples, embora o campo de marketing político apresente estratégias de uso das diversas ferramentas como solução para fazer sucesso eleitoral na rede. Para refletir sobre esses caminhos, é importante considerar valores contidos na rede, ou melhor, "sintomas de nossa época que as novas tecnologias amplificam” (SIBILIA, 2009, online).

Assim como os demais usuários das redes sociais, políticos em campanha (ou não), expõem bastidores e a própria intimidade para conquistar seguidores. Na tentativa de controlar a construção da própria reputação, manejam dosagens de informações institucionais, políticas e pessoais, criando intimidades não recíprocas e assimétricas, mas com potencial de repercutir e movimentar idéias e tendências.

$\mathrm{O}$ que move esses fluxos de informação e grupos de seguidores são as práticas "exibicionistas" e "confessionais" (SIBILIA, 2008, p. 24) perseguição da visibilidade, um crescente desejo de ser visto.

No mundo contemporâneo estão se transformando os modos em que se constrói esse eu que fala e que se mostra sem pausa, justamente porque necessita se exibir para ser alguém.

A conclusão é, portanto, que está acontecendo um deslocamento histórico do eixo em torno do qual se constrói o que é cada sujeito, e esses novos fenômenos tão presentes na In- 
ternet atual seriam um indício dessa mutação. Pensemos que naqueles tempos modernos que já começam a ficar envelhecidos - um período cujo auge ocorreu no século XIX e na primeira metade do $\mathrm{XX}$-, esse eixo se edificava em torno da "interioridade" de cada indivíduo, em volta de algo que se acreditava hospedado "dentro" de cada um e que guarnecia sua essência pessoal. Nos últimos anos, parece que esse eixo tem se deslocado em direção à superfície do corpo e, inclusive, cada vez mais, verte-se avidamente nas telas e em outras vitrines midiáticas. (SIBILIA, 2010, online)

A intimidade tem se convertido numa espécie de cenário no qual devemos montar o espetáculo de nós mesmos: a vitrine da própria personalidade.

O mundo contemporâneo não solicita introspecção, mas ele pede aos gritos visibilidade, celebridade, habilidades comunicativas e marketing de si mesmo. Por isso, cada um deve aprender a se administrar como uma empresa, posicionando sua marca no mercado das aparências. E essas ferramentas de exposição multimídia e interativas nos ajudam a conseguilo, além de nos capacitar para termos sucesso nessas arenas. (SIBILIA, 2010, online)

Assim como a televisão mudou a gramática política e os agentes precisaram dominar novas técnicas, as diferentes ferramentas da internet também precisam ser compreendidas, apropriadas as disputas simbólicas que podem ser travadas via rede. Se por um lado a campanha online se apresenta como solução. Por outro, a construção de redes online com propósito de debate de interesse público ainda é um grande desafio. Certamente a demanda por votos será mais determinante na busca dos ajustes para uso desses sistemas, do que o propósito de ampliar a participação do debate civil com vistas às eleições. Não por acaso, em ano de pleito, é possível perceber o crescimento do investimento virtual da maioria dos representantes políticos. 


\section{Os políticos se lançam na rede}

A Câmara dos Deputados anunciou oficialmente no início de junho deste ano sua página oficial ${ }^{4}$ no Twitter. Os internautas poderão acompanhar em tempo real todas as informações da casa legislativa.

Os levantamentos ainda iniciais feitos pela Câmara revelam algumas situações surpreendentes, considerando o mapa da acessibilidade no país. Os ${ }^{5}$ dados da Pesquisa Nacional por Amostra de Domicílios (Pnad) referentes a 2008 demonstram que geograficamente, a região Sudeste apresenta a maior taxa de uso da internet, com 40,3\% dos seus habitantes usando a rede. A região Centro-Oeste aparece logo atrás $(39,4 \%)$, influenciada pelo alto uso de web no Distrito Federal, onde 56,1\% dos habitantes afirmaram fazer uso da ferramenta. As regiões Sul (38,7\%), Norte $(27,5 \%)$ e Nordeste $(25,1 \%)$ aparecem logo atrás.

Contudo, proporcionalmente, a bancada mais conectada é a do Rio Grande do Norte, com seis dos oito deputados ligados no Twitter. Em números absolutos, São Paulo é o estado com mais deputados no microblog: 33. Entre as regiões, estão mais conectados os deputados do CentroOeste (44\%) e Sul (40,3\%).

Segundo levantamento da Secretaria de Comunicação Social, atualmente 179 dos 513 deputados têm páginas ativas no Twitter, o equivalente a $35 \%$ dos parlamentares. Na primeira pesquisa, realizada em julho de 2009, 74 parlamentares (14,4\%) mantinham microblogs - um aumento de $142 \%$. O levantamento considera apenas microblogs oficiais que estão ativos e têm atualização constante. Dos deputados com microblogs no Twitter, 37 são do PT, 31 do DEM, 23 do PSDB, 18 do PMDB, 13 do PP e 12 do PSB. Na divisão por regiões,

O estudo mostra ainda, que o DEM é o partido com o maior número de seguidores no Twitter, em comparação com os outros deputados. No total, os deputados democratas apresentaram 92.191 seguidores, enquanto os parlamentares do PT aparecem logo atrás com 90.224 leitores. A pesquisa analisou 295 deputados com perfis ativos na rede social de microblogs (tabela 1). 


\begin{tabular}{|c|c|c|}
\hline Partido & $29 /$ jan & $31 / \mathrm{mai}$ \\
\hline DEM & 40.640 & 92.191 \\
\hline PT & 40.958 & 90.224 \\
\hline PR & 6.621 & 53.439 \\
\hline PV & 26.191 & 40.330 \\
\hline PSB & 16.453 & 38.521 \\
\hline PSDB & 17.261 & 37.487 \\
\hline PMDB & 13.993 & 34.519 \\
\hline PDT & 13.008 & 30.592 \\
\hline PCdoB & 15.217 & 23.326 \\
\hline PP & 11.982 & 23.091 \\
\hline PMN & 10.145 & 14.436 \\
\hline PHS & 8.292 & 13.715 \\
\hline PSOL & 2.304 & 6.409 \\
\hline PPS & 2.532 & 5.532 \\
\hline PSC & 2.459 & 4.686 \\
\hline РТB & 2.593 & 4.375 \\
\hline
\end{tabular}

Tabela 1-Partidos no Twitter ${ }^{1}$

Segundo análise da secretaria, três fatores são os principais motivadores desse aumento. Um dos motivos é a proximidade das eleições, outro está relacionado com a própria atividade parlamentar - sendo um dos destaques no período observado: a votação do projeto Ficha Limpa - e também a volta de deputados titulares que ocupavam cargos em ministé- 
rios e secretarias estaduais e municipais.

$\mathrm{Na}$ tabela a seguir (tabela 2) é possível perceber claramente que a atividade parlamentar ou o perfil do deputado no uso das redes sociais deve ser fator relevante no número de seguidores, já que entre os dez com maior público praticamente não se repetem partidos, cada um é de uma sigla diferente. Nem mesmo os estados de origem são uma constante ou o nicho em que atuam. Ou seja, não se trata de estratégia partidária. Esse território parece totalmente atomizado, pessoalizado. Segue-se a persona.

\begin{tabular}{llll}
\hline Deputado & Partido & Estado & Seguidores 3 1/05 \\
\hline $\begin{array}{l}\text { FERNANDO } \\
\text { GABEIRA }\end{array}$ & PV & RJ & 36889 \\
$\begin{array}{l}\text { INDIO DA } \\
\text { COSTA }\end{array}$ & DEM & RJ & 26116 \\
\end{tabular}

$\begin{array}{lccc}\text { GERALDO } & \text { PR } & \text { RJ } & 22431 \\ \text { PUDIM } & & & \\ \text { PAULO } & \text { PT } & \text { RS } & 22148 \\ \text { PIMENTA } & & & \end{array}$

$\begin{array}{llll}\text { CIRO GOMES } & \text { PSB } & \text { CE } & 19601 \\ \text { PAULO } & \text { PDT } & \text { SP } & 19466 \\ \text { PEREIRADA } & & & \\ \text { SILVA } & & & \end{array}$

$\begin{array}{lllc}\text { LINCOLN } & \text { PR } & \text { MG } & 18200 \\ \text { PORTELA } & & & \\ \text { FÁBIOFARIA } & \text { PMN } & \text { RN } & 14428\end{array}$

$\begin{array}{llcc}\text { MANUELA } & \text { PCdoB } & \text { RS } & 13873 \\ \text { D'ÁVILA } & & & \\ \text { ULDURICO } & \text { PHS } & \text { BA } & 13715 \\ \text { PINTO } & & & \end{array}$

Tabela 2- Deputados com mais seguidores ${ }^{1}$ 
Já na tabela seguinte (tabela 3), é possível perceber que a participação de deputados conectados revela uma característica de estratégia mais partidária: é nos partidos alinhados mais à esquerda a predominância de parlamentares acessando as redes, de onde se pode concluir que apesar da habilidade e do investimento pessoal de cada liderança política, algumas siglas partidárias investem mais -por definição, estratégia ou característica -nesse modo de comunicação.

\begin{tabular}{|c|c|c|c|}
\hline Partido & NoTwitter & Total & $\begin{array}{l}\text { Percentual } \\
\text { conectado }\end{array}$ \\
\hline PSOL & 3 & 3 & 100,0 \\
\hline PCdoB & 11 & 12 & 91,7 \\
\hline PSB & 20 & 27 & 74,1 \\
\hline P'T & 58 & 79 & 73,4 \\
\hline PSDB & 42 & 58 & 72,4 \\
\hline PMN & 2 & 3 & 66,7 \\
\hline PDT & 14 & 23 & 60,9 \\
\hline DEM & 34 & 56 & 60,7 \\
\hline PP & 23 & 41 & 56,1 \\
\hline PSC & 8 & 16 & 50,0 \\
\hline PTC & 1 & 2 & 50,0 \\
\hline PRB & 3 & 7 & 42,9 \\
\hline PV & 6 & 14 & 42,9 \\
\hline PMDB & 8 & 90 & 42,2 \\
\hline PR & 17 & 42 & 40,5 \\
\hline PPS & 6 & 15 & 40,0 \\
\hline
\end{tabular}




\begin{tabular}{llll}
\hline PTB & 8 & 21 & 38,1 \\
PHS & 1 & 3 & 33,3 \\
PTdoB & & 0,0 & 0,0 \\
Brasil & 295 & 513 & 57,5 \\
\hline
\end{tabular}

Tabela 3-n ${ }^{\circ}$ deputados Twitter $^{1}$

Nesse quadro (tabela 3) é possível contemplar que grandes partidos têm índices menores de parlamentares conectados, apontando novamente para a idéia de que a participação na rede é uma ação atomizada dos políticos. Um caso ilustra de maneira mais clara: o deputado Fernando Gabeira aparece em primeiro lugar (tabela 2), como o parlamentar com maior número de seguidores no Twitter ( 36.889), já o seu partido, o PV, surge (tabela 3 ) como $13^{\circ}$ colocado, com um índice de 40,2\% de parlamentares conectados.

\section{Hiperpessoalização e participação: novas soluções de comu- nicação via rede?}

O crescimento da procura de políticos pelas interconexões que rede mundial de computadores oferece se explica pela gama de possibilidades que os aplicativos online oferecem. No campo econômico, há muito são desenvolvidos novos modelos de negócios e de marketing para anunciar. Isto se repete em todos os campos: das relações, da ciência, da educação, enfim, do compartilhamento de informações em vários níveis e segmentos.

A oportunidade inédita para o campo da comunicação é que o modelo de broadcasting- um para muitos- dá lugar a formatos híbridos, redesenhando o modo de produzir, emitir e receber informações de toda ordem. $\mathrm{O}$ antes passivo receptor conquista um protagonismo inédito e passa a transitar conteúdo. Essa reconfiguração - ainda que consideradas as assimetrias e diferenças de forças entre cidadãos comuns e meios da massa e indústria cultural-, muda a forma de consumir, incluindo aí produtos, serviços e conteúdos diversos. O grande ineditismo que interessa de políticos a celebridades e vendedores diversos é identificar com maior precisão perfis 
e demandas e a partir daí ajustar a oferta de acordo com as expectativas individuais ou de comunidades específicas.

A idéia de hiperpessoalização, de transformação para a "mídia de massa individual" é resultado de uma busca pelo pessoal, pela diferença que leva à personalização. "A mídia personalizada era uma das idéias da revolução digital no início da década de 90: a mídia digital iria nos "libertar" da "tirania" da mídia de massa, nos possibilitando consumir somente o que acharmos pessoalmente interessante" (JENKINS, 2006, p. 244). A cultura da personalização transpõe o ambiente midiático e se manifesta em diferentes perspectivas.

Num ambiente cada vez mais competitivo, vão se destacar os estabelecimentos que combinem todos esses avanços tecnológicos e outros mais com um atendimento personalizado, individualizado. Nesse sentido, durante uma campanha eleitoral, os candidatos podem se valer das vantagens da tecnologia como a facilidade e a rapidez na hora de testar propostas, ouvir feedback e estabelecer laços tratando o cidadão como um indivíduo especial. A tecnologia aparece nas estratégias de campanha para auxiliar no processo de cadastramento e formação de banco de dados dos eleitores, militantes e simpatizantes e como ferramenta eficaz para monitorar propostas, disseminar iniciativas, fomentar grupos de voluntariado, responder críticas e combater boatos.

A expectativa desses movimentos online é de ativar uma rede de redes e comunidades, embora a governabilidade sobre conteúdo e o controle sobre as ações em torno dos colaboradores seja praticamente impossível. O escritor Chris Anderson estabeleceu o termo Cauda Longa para definir o impacto nos negócios causado pelas novas tecnologias, com a transformação do mercado de massa, dominado por poucos hits, para um mercado de inúmeros nichos e de micro-hits.

As campanhas 2.0 também apostam na produção de conteúdo e ondas com autoria de simpatizantes e militantes, numa cauda longa de engajamento. Se a web não se presta como arena pública de deliberação, pelo menos, pode ser um espaço de influência nas discussões e agendamento de temas relevantes, sobretudo num período de intenso debate e movimentação da esfera pública como nas eleições. A tabela (tabela 4) reproduz as principais ferramentas, aplicativos e instrumentos online disponíveis para a comunicação política durante campanhas: 


\begin{tabular}{|c|c|c|c|c|c|}
\hline Ferramentas & $\begin{array}{l}\text { Torpedos } \\
\text { inteligentes }\end{array}$ & $\begin{array}{l}\text { Multiplicação } \\
\text { contatos }\end{array}$ & $\begin{array}{l}\text { Central de } \\
\text { Comunicação }\end{array}$ & \begin{tabular}{|l|} 
Monitora \\
Internet
\end{tabular} & $\begin{array}{l}\text { Recado de } \\
\text { voz }\end{array}$ \\
\hline O que é & $\begin{array}{l}\text { O eleitor } \\
\text { recebe } \\
\text { mensigens no } \\
\text { celular. Mais } \\
\text { de } 50 \text { pessoas } \\
\text { por segundo } \\
\text { podem ser } \\
\text { atingidas pelo } \\
\text { mecanismo. }\end{array}$ & $\begin{array}{l}\text { Simpatizantes } \\
\text { do candidato } \\
\text { indicam nomes, } \\
\text { e-mails e até } \\
\text { celulares de } \\
\text { amigos que } \\
\text { passarāo } \\
\text { receber a } \\
\text { informaçóes. }\end{array}$ & $\begin{array}{l}\text { O candidato } \\
\text { possui um site que } \\
\text { funciona como } \\
\text { central de redes } \\
\text { sociais, reunindo } \\
\text { (Twitter, Orkut e } \\
\text { Facebook) E } \\
\text { também envio de } \\
\text { torpedos e e-mail. }\end{array}$ & \begin{tabular}{|l} 
Relatórios \\
apre sentam \\
uma \\
minuciosa \\
análise sobre \\
a imagem do \\
candidato em \\
sites, blogs e \\
redes sociais.
\end{tabular} & $\begin{array}{l}\text { Ao receber } \\
\text { uma ligação } \\
\text { pelo } \\
\text { tele fone } \\
\text { (móvel ou } \\
\text { nāo), o } \\
\text { eleit or ouve } \\
\text { a woz do } \\
\text { candidato. } \\
\text { Ele pode } \\
\text { aceitar ou } \\
\text { nāo. }\end{array}$ \\
\hline $\begin{array}{l}\text { Como } \\
\text { funciona }\end{array}$ & $\begin{array}{l}\text { Na TV ou } \\
\text { internet } \\
\text { candidato } \\
\text { divulga } \\
\text { para }{ }^{\circ} \\
\text { interessados. } \\
\text { O eleitor envia } \\
\text { mensigem de } \\
\text { seu celular } \\
\text { autorizando } \\
\text { cadastro. }\end{array}$ & $\begin{array}{l}\text { O simpatizante } \\
\text { digita a senha } \\
\text { do próprio e- } \\
\text { mail num site. A } \\
\text { página mostra } \\
\text { uma lista com } \\
\text { todos os } \\
\text { contatos dele. O } \\
\text { internauta } \\
\text { seleciona } \\
\text { contatos que vai } \\
\text { liberar para a } \\
\text { campanha. }\end{array}$ & $\begin{array}{l}\text { Após escrever } \\
\text { uma mensagem, } \\
\text { basta selecionar } \\
\text { na central para } \\
\text { onde deseja enviá- } \\
\text { la. A mensagem é } \\
\text { disparada ao } \\
\text { mesmo tempo } \\
\text { para Redes } \\
\text { sociais, torpedo e } \\
\text { correio eletrônico }\end{array}$ & $\begin{array}{l}\text { Um } \\
\text { programa de } \\
\text { computador } \\
\text { vascullha na } \\
\text { web todas as } \\
\text { mençóes do } \\
\text { candidato. } \\
\text { Depois } \\
\text { registra quais } \\
\text { foram as } \\
\text { palavras mais } \\
\text { relacionadas } \\
\text { a ele em cada } \\
\text { site. }\end{array}$ & $\begin{array}{l}\text { Um } \\
\text { software } \\
\text { que grava a } \\
\text { voz do } \\
\text { candidato e } \\
\text { dispara } \\
\text { milhares de } \\
\text { mensagens } \\
\text { ao mesmo } \\
\text { tempo. }\end{array}$ \\
\hline
\end{tabular}

Tabela 4: Levantamento do jornal ZH 16.05.2010

Todas essas ferramentas ainda estão por ser testadas em diferentes ambientes, têm seus percentuais de sucesso e de fracasso, mas certamente estarão presentes nas campanhas eleitorais de todo o país empreendidas neste ano. São o arsenal de profissionais de marketing político dispostos a encantar candidatos e levar diferenciais para a disputa. A real eficiência ainda deverá ser verificada.

Ainda que o aumento do acesso e o crescimento da participação de políticos já tenha sido registrado, o uso da rede ainda comporta muitas variáveis. Os maiores graus de uso são registrados entre brasileiros com maior escolaridade (80,4\% dos usuários com 15 ou mais anos de estudo usam a web), embora os dados do IBGE indiquem que o acesso cresceu 
mais entre os menos escolarizados.

A porcentagem dos brasileiros com menos de quatro anos de instrução com acesso à web, segundo o IBGE, quase triplicou, saltando de 2,5\% em 2005 para 7,2\% em 2008. Os dados mais recentes da Pesquisa Nacional por Amostra de Domicílios (PNAD), divulgada em setembro deste ano pelo Instituto Brasileiro de Geografia e Estatística (IBGE) revelam que o contingente de pessoas com 10 anos ou mais que acessam a internet cresceu 21,5\% no Brasil em 2009, passando de 55,9 milhões no ano anterior para 67,9 milhões. No total, $41,7 \%$ dos brasileiros dizem ter tido acesso ao serviço. É um crescimento que acumula 112,9\% desde 2005, quando havia 31,9 milhões de pessoas que declaravam ter usado a rede de computadores. Entre 2005 e 2009, houve aumento da proporção de pessoas que utilizaram a internet em todas as regiões do país.

O acesso em casa já é realidade para 16 milhões de residências no Brasil, ou 27,4\% do total. É a primeira vez que o Brasil passa a ter uma conexão para cada quatro residências: em 2008, havia conexão em 23,8\% das casas. A tabela (tabela 5) abaixo mostra o ranking de crescimento nas regiões do país.

\begin{tabular}{|lll|}
\hline Regî̉o & Proporçắo usuários / 2005 & Proporçáo usuários/ 2009 \\
\hline Sudeste & $26,2 \%$ moradores & $48,1 \%$ moradores \\
\hline Centro- Oeste & $23,4 \%$ moradores & $47,2 \%$ moradores \\
\hline Sul & $26,2 \%$ moradores & $45,9 \%$ moradores \\
\hline Norte & $12 \%$ moradores & $34,3 \%$ \\
\hline Norde ste & $11,9 \%$ moradores & $30,2 \%$ \\
\hline
\end{tabular}

Tabela 5- Fonte IBGE ${ }^{1}$

A região Norte teve o maior aumento proporcional no contingente, de 213,9\% entre 2005 e 2009. De 2008 a 2009, as mulheres avançaram mais que os homens com relação ao acesso à internet. $\mathrm{O}$ aumento no contingente de homens foi de 20,0\%, e no de mulheres alcançou 22,9\%.

Embora tenha crescido entre todas as faixas etárias, o uso de internet teve aumento proporcional maior entre os mais jovens. Entre os brasileiros de 10 a 14 anos, 58,8\% acessaram a rede em 2009. A maior presença on-line está na faixa entre 15 a 17 anos, com 71,1\% de acesso, contra 68,7\% para os brasileiros de 18 ou 19 anos. Ainda com relação a dados de 2008, há 
uma característica interessante entre os excluídos do universo online.

Entre os estimados 104,7 milhões de brasileiros que não usaram a internet no período do levantamento, as justificativas têm relação tanto com a falta de necessidade ou desejo $(32,8 \%)$, pela falta de conhecimento $(31,6 \%)$ ou pela falta de oportunidade de acesso (30\%).Ou seja, a falta de oportunidade e a dificuldade de acesso se equilibra ao percentual de quem não acessou por falta de vontade.Ainda que o dispositivo tecnológico esteja ao alcance, ainda é importante a motivação para acessá-lo e mais do que isso, usá-lo como meio para o debate. "A internet reduz os custos de participação política e pode proporcionar um meio de interação através do qual o público e os políticos podem trocar informações, consultar e debater, de maneira direta, contextualizada, rápida e sem obstáculos democráticos" (MAIA, 2002, p.48).

Mas é preciso levar em conta que para fortalecer a democracia "são necessárias não apenas estruturas comunicacionais eficientes e instituições propícias à participação, mas também devem estar presentes a motivação correta, o interesse e a disponibilidade dos próprios cidadãos para se engajar nos debates" (Idem, 2002, p. 50).

Num contexto de desprestígio político e desinteresse da população pela discussão pré-eleitoral se justifica a dúvida sobre qual o perfil do internauta brasileiro que participa de discussões políticas. Em ${ }^{6}$ artigo o pesquisador Rogerio Schlegell visa traçar o perfil do "Internauta brasileiro: perfil diferenciado, opiniões indiferenciadas", com o objetivo de contribuir para melhorar a compreensão das relações entre o uso da internet, de um lado, e a participação política dos cidadãos, de outro.

Sua ênfase é nos fatores que determinam o uso regular da internet e no perfil do internauta em termos de participação e valores relacionados à política. A análise dos dados do survey Latinobarómetro de 2007 aponta a idade e a escolaridade como principais determinantes do uso da internet no Brasil, sendo que a ocupação e um proxy para renda não tiveram impacto consistente na chance de conectar-se, contrastando com os casos de Argentina e Chile.

Ao mesmo tempo, o público que integra a comunidade on-line mostrou maior mobilização, em termos de participação política tradicional, e pouca diferenciação em matéria de opiniões sobre política, na comparação com os não-usuários da nova tecnologia. Essas evidências sugerem que a conexão ao mundo digital tende a dar voz a segmentos que já contam com acesso privilegiado a governantes e elaboradores de políticas, sobretudo por seu capital cultural, embora haja sinais da existência de oportunidades para 
outros setores sociais. Uma revelação importantíssima para apreciar a idéia desta pesquisa, que é de observar se a rede serve como canal de vozes periféricas. Os estudos de Schebell também indicam que a importância do "digital divide" no país deve ser relativizada, uma vez que os internautas não apresentam opiniões com orientação claramente destoante do restante da população.

No estudo Metodologia de pesquisa de blogs de política: análise das eleições presidenciais de 2006 e do movimento "Cansei”, Marcelo Burgos Pimentel dos Santos; Cláudio Luis de Camargo Penteado e Rafael de Paula Aguiar Araújo compreendem os blogs enquanto espaço de comunicação e atores políticos que trazem uma nova dinâmica para as relações sociais. $\mathrm{O}$ trabalho discute o uso dessa nova ferramenta e suas implicações para a compreensão do jogo político na contemporaneidade. Os autores acompanharam alguns dos principais blogs durante as eleições presidenciais de 2006 e o debate do movimento "Cansei”. A análise, em geral, gira em torno do posicionamento político dos participantes, muitas vezes deixando de lado o tema central proposto pelo 'blogueiro'. Foi comprovada a hipótese de que os blogs são importantes ferramentas capazes de ampliar a participação política, mas que, efetivamente, os debates estabelecidos nos fóruns de discussão são superficiais, caracterizados pela falta de qualidade dos argumentos, presença de avaliações morais, ausência de propostas e análises críticas.

\section{Justaposições na rede: opinião e dimensões do público e pri- vado}

Considerando as ferramentas disponíveis, o aumento de políticos que empreendem esforços na internet para conquistar o eleitor e o perfil dos internautas que participam politicamente, é imprescindível avaliar como tudo determina releituras dos conceitos de opinião pública, de espaço público e privado. Afinal, políticos e cidadãos estão experimentando novos laços de exposição, intimidade, personalização para debater questões de interesse público. Como o candidato entra na rotina, na vida privada do cidadão, tratando-o como parceiro especial, na tentativa de capturar seu voto e seu engajamento, particularizando e compartimentando questões coletivas, vale perguntar: estão diluídas as fronteiras entre o público e o privado, em quais terrenos se movimentam as ações de comunicação política nas cam- 
panhas eleitorais?

A pesquisadora Mariângela Furlan Haswani ${ }^{7}$ refere Hanna Aren$\mathrm{dt}$, para quem o termo espaço público surge com duas qualificações contrastantes: espaço agonístico ${ }^{8}$ e associativo (ARENDT apud BENHABIB, 1993, p.76). Associativo é o conceito em que qualquer lugar pode tornar-se um espaço público se significar também espaço de poder, de possível intervenção política. Liszt Vieira ao comentar o modelo diz:

\begin{abstract}
A oposição entre a concepção agonística e a associativa de espaço público corresponde à distinção entre a experiência grega e a experiência moderna de política. $\mathrm{O}$ espaço agonístico da polis tornou-se possível pelo caráter exclusivo, moralmente homogêneo e politicamente igualitário da sociedade. Para os modernos, no entanto, o espaço público é essencialmente poroso. Não pode ter seu acesso nem sua agenda de debate predefinidos por critérios de heteroneidade moral e política (VIEIRA, 2001,p.55)
\end{abstract}

A mídia de massas é um componente fundamental que reconfigura os espaços públicos e a disputa de poder, sendo em grande parte responsável pela produção da agenda pública (MIGUEL, 2010, p 8). Por ser capaz de formular as preocupações coletivas influencia no comportamento de líderes políticos em busca de visibilidade. A mídia tornou-se o principal instrumento de contato entre a elite política e o cidadão comum (MIGUEL, 2010,p 7). Portanto, é de se esperar que a busca da visibilidade seja uma constante por quem precisa sistematicamente responder, expor e fazer a defesa de projetos. São questões postas para deliberação pública que terão maior ou menor interesse dependendo do espaço/tempo e do enquadramento que receber dos meios de comunicação. "A mídia fornece os esquemas narrativos que permitem interpretar os acontecimentos. $\mathrm{Na}$ verdade, ela privilegia alguns desses esquemas em detrimento de outros" (GOFFMAN apud MIGUEL, 2010, p 10).

Se a presença no noticiário parece determinante para o sucesso ou fracasso de um mandato parlamentar ou executivo, a boa gestão da reputação nas redes sociais aparece como elemento novo das disputas por visibilidade e agendamento. Sem o filtro dos meios, a liderança política pode propor os temas que considerar mais pertinentes e direcionar aos perfis que mais interessem. Outro aspecto relevante no uso das mídias digitais é o controle da visibilidade, com a oferta das quotas de intimidade na medida em que mais interesse. Isso não significa que seja possível controlar boatos, 
fofocas, imagens constrangedoras e até mesmo perfis falsos na web, mas também é característica da rede conviver e depurar conteúdos suspeitos.

Essa linha direta conquistada pela liderança política permite não prescindir da mídia para agendamento e discussão de temas, mas pelo contrário, utilizar os critérios de noticiabilidade para prender a atenção do cidadão e até mesmo conseguir repercutir desde seu pequeno espaço virtual, os assuntos que lhe interessam. A necessidade dos atores sociais de criarem acontecimentos noticiáveis fica facilitada, como também a dramatização.

\begin{abstract}
$\mathrm{Na}$ sociedade contemporânea, a publicidade dos discursos políticos assume uma dimensão performática. Isso não significa que a política tenha perdido consistência, masque seus agentes, ciosos da importância da sua imagem pública, precisam, para atuar eficazmente nesta esfera, de uma certa competência comunicativa (PRUDÊNCIO, 2010, p 262).
\end{abstract}

\title{
Considerações finais
}

Se o conjunto de dispositivos tecnológicos será apropriado de maneira correta pelos profissionais de comunicação da campanha e dos próprios políticos, ainda é uma questão sem respostas conclusivas. Mais ainda, o que deve mudar na construção dos discursos e na própria atuação política, deve demandar muita análise. $O$ fato é que aumenta o fluxo de informação "mas aquelas que se constituem no espaço publico precisam ainda concorrer com todas as outras" (PRUDÊNCIO, 2010, p. 263).

A ampla maioria dos estudos de mídia e política tem como principal tema o impacto dos meios de comunicação. Certamente, é esse o foco de interesse com relação às redes sociais. Qual seu impacto no processo comunicativo-eleitoral? Será possível isolar essa variável e empreender estudos que respondam os graus de resultado que o uso das mídias digitais alavancam na decisão final do eleitor? As trocas simbólicas que correm pelos bytes podem ser mensuradas, são influentes, ressignificam um novo tipo de opinião pública, mais coletiva ou mais atomizada?

A característica principal desta nova comunicação política é a circulação bidirecional das mensagens, não só dos partidos ou das instituições para o cidadão- como até bem pouco tempo ocorria- mas também do cidadão, do militante. $O$ futuro eleitor pode emitir suas mensagens nos contextos mais diversos para que sejam ouvidos por seus representantes 
políticos, por seus vizinhos, de comunidades virtuais ou não, amigos,pelos próprios meios de comunicação ou por quem se interesse em ouvi-los. Esse é um modelo que supera o sistema de comunicação vertical e "passa de uma interação intermitente e frágil, para uma contínua e intensa” (FERNANDEZ, 2007).

Essa circunstância faz com que essas novas ferramentas tecnológicas adquiram uma dimensão distinta da de um simples canal de comunicação e passem a refletir pensamentos, atuações e intenções políticas de todos os agentes desses canais.

Nesse cenário em transformação ainda cabem inúmeras indagações: se os partidos vão explorar essas possibilidades como meio para incrementar a participação democrática ou meramente como propaganda e marketing; se a facilidade de acesso a intercâmbio de informações pode aumentar o interesse político dos cidadãos ou se os grupos já organizados e com interesses prévios de participação social e política é que se beneficiam das ferramentas e ainda se mudam, em função de tudo isso, a comunicação política tradicional e a cobertura política dos meios de referência. Um campo vasto, complexo e fascinante em vários aspectos.

\section{Referências}

BENHABIB, S. Models of public space: Hannah Arendt, the Liberal tradition, and Jürgen Habermas. In: CALHOUN, C. (Ed.). Habermas and the public sphere. 4. ed. Massachusetts: The MIT Press, 1996. p. 73-98.

CHAIA, Vera e BRAGA, Sérgio- Dossiê Internet e Política- Revista de Sociologia e Política. vol. 17, no 34, Curitiba, 2009.

FERNÁNDEZ CRESPO, Montserrat. (2007). Internet, Blogs y Politica 2.0. http://masterpolitica.wordpress.com/2008/07/04/tesina-publicada/

GOMES, Wilson. Transformaçôes da politica na era da Comunicação de massa. São Paulo: Paulus, 2004.

HASWANI, M. Quem agenda quem: Estudo das relações entre assessorias de imprensa do setor público e veículos jornalísticos na cidade de São Paulo. São Paulo, 2003. Dissertação de Mestrado. Escola de Comunicações e Artes. Universidade de São Paulo.

JENKINS, Henry. Cultura da Convergência. São Paulo: Aleph, 2006.

MAIA, Rousiley, Wilson GOMES. Comunicação e Democracia: Problemas 
e perspectivas. São Paulo: Editora Paulus, 2008

MIGUEL, Luis Felipe, BIROLI, Flávia (orgs). Midia, representação e democracia. São Paulo: Hucitec, 2010.

PRUDENCIO, Kelly. Mobilizar a opinião pública:sobre a comunicação dos ativistas políticos. In: MIGUEL, Luis Felipe, BIROLI, Flávia (orgs). Midia,representação e democracia. São Paulo: Hucitec, 2010.

RECUERO, Raquel. Redes sociais na internet. Porto Alegre: Sulina, 2009. . Redes sociais online e redes sociais offline. Disponível em: http:// pontomidia.com.br/raquel/arquivos/redes_sociais_online_x_redes_sociais_offline.html. Acesso em fevereiro de 2010.

SIBILIA, Paula. O show do eu: A intimidade como espetáculo. São Paulo: Nova Fronteira, 2008.

. Entrevista Paula Sibilia Revista do Instituto Humanitas Unisinos. Disponível em: www.ihuonline.unisinos.br, Acesso em junho de 2010.

\section{Notas}

[1] Fonte: Secretaria de Comunicação da Câmara dos Deputados

[2] Fonte: www.jrmetrics.com, consultado em fevereiro de 2010.

[3] Fonte: http://idgnow.uol.com.br/internet/2009/12/11, consultado em junho de 2010)

[4] http://twitter.com/CamaraDeputados visitada em 18 de junho de 2010.

[5] http://idgnow.uol.com.br/internet/2009/12/11/acesso-a-internet-no-brasil-cresce75-3-em-tres-anos-afirma-ibge

[6] Dossiê Internet e Política- Revista de Sociologia e Política, vol. 17, no 34, Curitiba, 2009.

[7] Fonte: "Dimensões e abrangências do conceito de público", de Mariângela Furlan Haswani Docente da Universidade de São Paulo. Tem experiência na área de Comunicação , com ênfase em Jornalismo e Editoração. Atuando principalmente nos seguintes temas: Comunicação Governamental, Comunicação pública, Comunicação estatal, Participação política - Brasil, Relações ../

[8] Agonístico para Arendt é um espaço de competição por reconhecimento e aclamação, em que se busca a perpetuação das coisas humanas a partir do heroísmo e da superioridade 
Sandra Bitencourt

\section{* Sandra Bitencourt}

Mestre em comunicação e educação pela Universidade autônoma de Barcelona e doutoranda do PPGCOMUFRGS

E-mail: contato@sandrabitencourt.com.br 